\title{
Ameliorative Function of a Probiotic Bacterium, Lactobacillus rhamnosus MR1 on Acute Iron Toxicity in Rats
}

\author{
Abdolrazagh Marzban ${ }^{1(D)}$, Majid Zeinali ${ }^{2}$ (D), Kamal Razavi-Azarkhiavi ${ }^{3}$ (D), Manoocher Teymouri ${ }^{4}$ (D), \\ Gholamreza Karimi ${ }^{3}$ (D), Abolghasem Danesh ${ }^{5, * \text { (ID }}$
}

1 Razi Herbal Medicines Research Center, Lorestan University of Medical Sciences, Khorramabad, Iran; marzban86@gmail.com (A.M.);

2 Social Security Organization (SSO), Mashhad, Iran; Majid.zeinal@gmail.com (M.Z.);

3 Faculty of Pharmacy, Mashhad University of Medical Sciences, Mashhad, Iran; Pharmaceutical Research Center, Mashhad University of Medical Sciences, Mashhad, Iran; Kamal.razavi-azar@yahoo.com (K.R.A.); KarimiG@mums.ac.ir (G.K.);

4 Natural Products and Medicinal Plants Research Center, North Khorasan University of Medical Sciences, Bojnurd, Iran; teymourim901@mums.ac.ir (M.T.);

5 Biotechnology Research Center, Pharmaceutical Technology Institute, Mashhad University of Medical Sciences, Mashhad, Iran; DaneshA@mums.ac.ir (A.D.);

* Correspondence: DaneshA@mums.ac.ir;

Received: 4.11.2020; Revised: 2.12.2020; Accepted: 4.12.2020; Published: 10.12.2020

\begin{abstract}
Overuse of iron supplements can lead to an acute inflammation of the gastrointestinal tract. This study investigates the ameliorative and prophylactic effects of a probiotic bacterium, L. rhamnosus MR1, on acute iron poisoning in rats. In this study, a probiotic strain was isolated from yogurt and characterized for its probiotic properties, including antibiotic-resistant, bile salt (BS) and acid resistance, iron tolerance, cell hydrophobicity of the bacterial cells. The anti-inflammatory effect of strain MR1 was studied on the iron exposed-Caco-2 cell line. In vivo experiments were conducted for the assessment of survival in rats overdosed with treatment. These findings indicate high bacterial tolerance in acidic conditions, high concentrations of bile salts, and iron. The anti-inflammatory effects of strain MR1 were confirmed by decreasing the concentration of pro-inflammatory cytokine IL- 8 and increasing anti-inflammatory cytokine IL-4 in treated groups. Prophylactic and acute effects of strain MR1 in rats caused a significant reduction in intestinal iron poisoning by $50 \%$ during $6 \mathrm{~h}$. Prophylactic regimen by $L$. rhamnosus MR1 increased the viability of about $33 \%$ in acutely poisoned rats. Since no report is found in the current literature about the effect of probiotic supplements on iron's acute toxicity, these interesting results can provide a useful background for further studies on dietary supplements.
\end{abstract}

Keywords: Lactobacillus rhamnosus MR1; acute iron toxicity; bacterial probiotics; oral administration.

(c) 2020 by the authors. This article is an open-access article distributed under the terms and conditions of the Creative Commons Attribution (CC BY) license (https://creativecommons.org/licenses/by/4.0/).

\section{Introduction}

Iron is one of the most essential elements in the body that plays a fundamental role in many biological processes. Iron contained in heme, which includes hemoglobin and myoglobin, is ferrous iron $\left(\mathrm{Fe}^{2+}\right)$; however, more than $25 \%$ of the iron content of the body is stored in the complex with hemosiderin, ferritin, and transferrin in tissues such as the liver, spleen, and bone marrow [1]. Nowadays, iron supplements have attracted particular attention in society due to increasing iron deficiency [2]. On the other hand, excessive iron consumption 
can lead to severe complications, including corrosive injury of the gastrointestinal tract and hemorrhagic necrosis of the gastric mucosal membrane. Since excessive iron in the body cannot bind to iron carriers, it converts to toxic free radicals causing acute intoxication $[3,4]$. Acute iron poisoning often occurs when an individual orally consumes a large number of ironcontaining supplements. Complications of acute poisoning due to increased iron intake can cause various symptoms such as nausea, vomiting, abdominal pain, and diarrhea [5]. Iron in the form of ferrous sulfate is a common form of pharmaceutical preparations available in multiple formulations for oral and injectable applications. Oral iron supplements such as drops, syrups, elixirs, capsules, and tablets often contain $325 \mathrm{mg}$ of ferrous sulfate. Only about $20 \%$ of them are absorbable by the intestine. In iron overdose cases, an increase in serum iron up to $500 \mu \mathrm{g} / \mathrm{dl}$ appears severe clinical complications that may lead to death [6].

As aforementioned, the first useful step to prevent acute oral poisoning is the inhibition of iron intake in the gastrointestinal system. Therefore, some compounds and drugs that can bind to iron in the gastrointestinal tract could be applied for preventing iron intoxication. One of the most essential gastrointestinal hemostatic regulators is gut microbial flora that acts as a pivotal mediator in the absorption of substances and the neutralization of harmful compounds $[4,7]$. Probiotics constitute a live part of fermented dairy products that provide many health benefits to the host. Many studies have documented the role of probiotic bacteria like Lactobacillus and Bifidobacterium species in the gastrointestinal tract's metabolic and physiological balance [8,9]. Studies have shown that probiotics are healthy, safe, and easily available because they have originated from food sources. Several reports have claimed the protective role of probiotics in heavy metals, chemical compounds, and toxins [10]. This study aimed to investigate the effects of a probiotic bacterium isolated from yogurt from iron sulfate's acute toxicity in rats.

\section{Materials and Methods}

\subsection{Bacterium isolation and identification.}

Several probiotic bacteria were isolated from yogurt fermented from goat milk. Before the isolation experiment, the yogurt sample was maintained at room temperature for $72 \mathrm{~h}$. Then, $1 \mathrm{ml}$ of yogurt sample was taken in a glass tube and diluted 10-fold series by sterile distilled water. A 10- $\mu$ l volume of each dilution was spread on MRS (Man, Rogosa, and Sharpe) agar plates. The plates were then incubated at $37{ }^{\circ} \mathrm{C}$ for $72 \mathrm{~h}$ until different bacterial colonies appeared over the agar media. The single purified colonies were characterized based on their morphology, biochemical characterization, and 16S rRNA-based phylogenetic study. These isolates were frozen at $-70{ }^{\circ} \mathrm{C}$ in MRS broth containing $20 \%(\mathrm{v} / \mathrm{v})$ glycerol and maintained until further investigations. Among the isolated strains, L. rhamnosus MR1 was selected based on the most resistant bacterium to ferrous sulfate into MRS broth compositions.

\subsection{Bile salt and $\mathrm{pH}$ resistance.}

The survival test was conducted according to a method described by Sharma et al. (2019) with a little modification [10]. All experiments were performed in different conditions such as pH (2-8) and sodium taurocholate (0.1-3\%) in sterile glass tubes containing $10 \mathrm{ml}$ of MRS broth medium. Overnight grown bacterial inoculum in the volume of $100 \mu 1$ containing $1.5 \times 10^{8}$ cells $/ \mathrm{ml}$ was inoculated in glass tubes, incubated at $37^{\circ} \mathrm{C}$ for $1 \mathrm{~h}$. After that, $100 \mu \mathrm{lof}$ 
each sample was taken, 10-fold diluted and spread on MRS agar plate. Finally, the number of colonies was determined using a colony counter (Gallenkamp, England).

\subsection{Antibiotic resistance of L. rhamnosus MR1.}

The antibiotic resistance of L. rhamnosus MR1 was characterized based on the Clinical and Laboratory Standards Institute (CLSI) guideline using the disc diffusion method. For this, the bacterial inoculum $\left(1.5 \times 10^{8} \mathrm{CFU} / \mathrm{ml}\right)$ was spread on MRS agar using a sterile swap. For this, ten antibiotics discs including cephalexin $(30 \mu \mathrm{g})$, ampicillin $(10 \mu \mathrm{g})$, penicillin $\mathrm{G}(2 \mathrm{IU})$, tetracycline $(10 \mu \mathrm{g})$, erythromycin $(15 \mu \mathrm{g})$, chloramphenicol $(30 \mu \mathrm{g})$, streptomycin $(10 \mu \mathrm{g})$, kanamycin $(30 \mu \mathrm{g})$, azithromycin $(15 \mu \mathrm{g})$ and ciprofloxacin $(5 \mu \mathrm{g})$ were used. Different antibiotic paper discs were placed on the plates and incubated at $37{ }^{\circ} \mathrm{C}$ for $24 \mathrm{~h}$. A ruler measured the diameter of the growth inhibition zone.

\subsection{In vitro cell adhesion ability of L. rhamnosus MRI.}

The adhesion ability of L. rhamnosus MR1 was investigated on Caco-2 cells in the presence of iron sulfate. For this, Caco-2 cells were seeded in 24-well culture plates in high glucose DMEM supplemented with $10 \%$ FBS and penicillin/streptomycin $(100 \mathrm{U} / \mathrm{ml})$ at $37^{\circ} \mathrm{C}$ in a humidified atmosphere with $5 \% \mathrm{CO}_{2}$ until $80 \%$ confluent monolayer cells were formed. After that, the culture medium was removed from the wells, washed with PBS, and replaced with a fresh medium containing different numbers of the bacterial cells $\left(10^{6}, 10^{7}\right.$, and $10^{8}$ $\mathrm{CFU} / \mathrm{ml}$ ) supplemented with $30 \mathrm{mg} / \mathrm{l}$ of ferrous sulfate. After $4 \mathrm{~h}$ the incubation, the culture medium was removed and washed twice with PBS. Adherent bacterial cells were detached using $1 \%$ Triton X-100. The number of viable bacterial cells was counted by the colony counting method on MRS agar plates.

\subsection{Ferrous ion tolerance assay.}

The iron resistance pattern was determined using MIC and MBC methods against different concentrations $(0-500 \mathrm{mg} / \mathrm{ml})$ of ferrous sulfate as previously [11]. To assay MIC for Iron treatment, ferrous sulfate stock $(500 \mathrm{mg} / \mathrm{ml})$ was prepared, and then 2-fold dilutions were performed until it reached the lowest concentration. The overnight bacterial cells were grown in MRS broth containing one of the Iron diluted solutions. After $24 \mathrm{~h}$ incubation, the bacterial growth rate was examined by measuring the culture media's optical density at $600 \mathrm{~nm}$. MIC was defined as the lowest iron concentration at which there was no visible growth in optical density $\left(\mathrm{OD}_{600}\right)$. MBC has defined as the lowest concentration of the iron that no colony was growing on the MRS agar plates.

\subsection{Cell hydrophobicity.}

Hydrophobic of the bacterial cells was evaluated using n-hexane and olive oil as a nonpolar phase according to a method described by Heravi et al. (2011) [12]. A bacterial suspension with an initial optical density of 0.3 (absorbance wavelength of $600 \mathrm{~nm}$ ) was prepared from overnight bacterial culture. The effect of Ferrous sulfate, $\mathrm{pH}$, and bile salt on the cell hydrophobicity were examined at the $\mathrm{pH}$ range of 2-8 and the different concentrations of ferrous sulfate $(0-300 \mathrm{mg} / \mathrm{l})$ and bile salt $(0.5-3.0 \%)$. Two-milliliter volumes of bacterial suspension were mixed with $500 \mu \mathrm{l}$ of n-hexane and olive oil, then vortexed for 2 min and kept at room temperature for $1 \mathrm{~h}$. Subsequently, the aqueous phase was taken for estimating bacterial 
cell density using determining the optical density (OD600 nm). The hydrophobicity index was calculated as the following formula:

$$
\text { Hydrophobicity index }=\frac{\text { OD initial }- \text { OD final }}{\text { OD initial }} \times 100
$$

\subsection{Anti-inflammatory activity of L. rhamnosus MR1.}

The anti-inflammatory function of L. rhamnosus MR1 was examined on the Caco-2 cell line in 24-well plates. The inflammatory response was stimulated by treating the cells with 10 or $30 \mathrm{mg} / \mathrm{ml}$ of ferrous sulfate. Additionally, one group was also stimulated with $250 \mathrm{ng} / \mu \mathrm{l}$ of lipopolysaccharide (LPS). Each well was treated with $200 \mu 1$ of $10^{8} \mathrm{CFU} / \mathrm{ml}$ of L. rhamnosus MR1 in MRS broth and incubated in the conditions described earlier for $3 \mathrm{~h}$. Three untreated groups, including Fe-stimulated, LPS-stimulated, and un-stimulated groups, were considered for comparative controls. After that, the culture media were taken to measure the levels of immunomodulatory cytokines, including TNF- $\alpha$ and IL-4, using ELISA kits (ZellBio, GmbH, Germany).

\subsection{Antioxidant activity of L. rhamnosus MRI.}

The antioxidant property of L. rhamnosus MR1 metabolites was quantitatively determined using DPPH assay method. The metabolites of an overnight bacterial culture $(\mathrm{OD}=1.0$ at $600 \mathrm{~nm})$ were extracted via filtration using $0.22 \mu \mathrm{m}$ Whatman filter paper. The filtrate was diluted two-fold, and $1 \mathrm{ml}$ of serial dilutions was mixed with $1 \mathrm{ml}$ of DPPH solution $(0.05 \mathrm{mM})$. After that, the samples were incubated at $37{ }^{\circ} \mathrm{C}$ in darkness for $30 \mathrm{~min}$. Their absorbance was determined at $517 \mathrm{~nm}$ using a UV-Visible spectrophotometer (Jenway UV6420, UK). Ascorbic acid (AA) was used as a standard positive control, and Deionized water was a blank sample. The following equation was used for calculating the scavenged DPPH radicals by bacterial metabolites.

$$
\text { Scavenging capacity }(\%)=\frac{1-\text { OD Sample }}{\text { OD Blank }} \times 100
$$

\subsection{Animal experiments.}

A total of 20 male Wistar rats (aged 9 weeks; weighing 200-250 g) were obtained from the Pasteur Institute Animal center, Tehran, Iran. To acclimate the animals to laboratory conditions, they were subjected to regular periods of $12 \mathrm{~h}$-light and $12 \mathrm{~h}$-dark. Relative humidity and room temperature were adjusted at $4 \%$ and $24 \pm 1{ }^{\circ} \mathrm{C}$, respectively. Two groups were served to study the prophylactic effect of probiotics. One group was fed a standard diet without probiotics (control), and another was fed a probiotic-supplemented diet $\left(3 \times 10^{8} \mathrm{cells} / \mathrm{g}\right.$ dried substance). These groups were kept for 3 weeks under the twice-a-day feeding regimen. After this period, control and treatment groups were gavaged by $1 \mathrm{ml}$ of the diet without probiotics and $1 \mathrm{ml}$ of probiotic-supplemented diet, respectively. Another experiment was conducted to examine the effect of probiotic administration on acute toxicity induced by ferrous sulfate. Therefore, two acute experiment groups (control and treatment) were fed the same regimen for prior groups. One hour later, all groups were gavaged with $500 \mathrm{mg} / \mathrm{l}$ ferrous sulfates. Finally, according to a time-schedule, all rats were anesthetized by intraperitoneal injection of ketamine/xylazine (90 mg ketamine plus $10 \mathrm{mg}$ xylazine per $\mathrm{kg}$ animal weight). Blood samples were obtained from the retro-orbital venous plexus by sterilized glass capillary 
tubes. Firstly, basal blood iron was determined before overdose iron administration. Then, blood samples were obtained after 1, 4, and $6 \mathrm{~h}$ of iron administration. Blood samples were collected in $2 \mathrm{ml}$ microvials, maintained at laboratory temperature for $30 \mathrm{~min}$, and then centrifuged at $3500 \mathrm{rpm}$ for $15 \mathrm{~min}$ to separate the serum. Serum iron was measured by flame atomic absorption spectrophotometry. All animal experiments were conducted according to the human and animal ethical committee's protocol, Mashhad University of Medical Sciences.

\subsection{Statistical analysis.}

The results obtained from the experiments were presented as mean $\pm \mathrm{SD}$. The data values were analyzed by one-way analysis of variance (ANOVA) followed by the Tukey post hoc test. All analyses were performed using GraphPad Prism Version 5.0 (GraphPad, Softwares Inc., San Diego, CA, USA). A confident level of $95 \%$ was considered for significance at P-value $<0.05$.

\section{Results and Discussion}

\subsection{Bacterium isolation and identification.}

Amongst the 9 isolates, the most resistant Lactobacillus strain to ferrous sulfate with the highest tolerance of about $100 \mathrm{mg} / \mathrm{l}$ ferrous sulfates was primarily selected, identified, and deposited as L. rhamnosus MR1 (accession number: KT215644.1) in the Genebank, NCBI according to $16 \mathrm{~S}$ rRNA sequencing and global alignment in the BLAST online software. The bacterium was kept in $20 \%$ glycerol for the subsequent studies. Figure 1 represents the closest strains and relation between different Lactobacillus genus spices that their 16S rRNAs were retrieved from NCBI Genebank, and the corresponding phylogenetic tree was constructed by Mega X software.

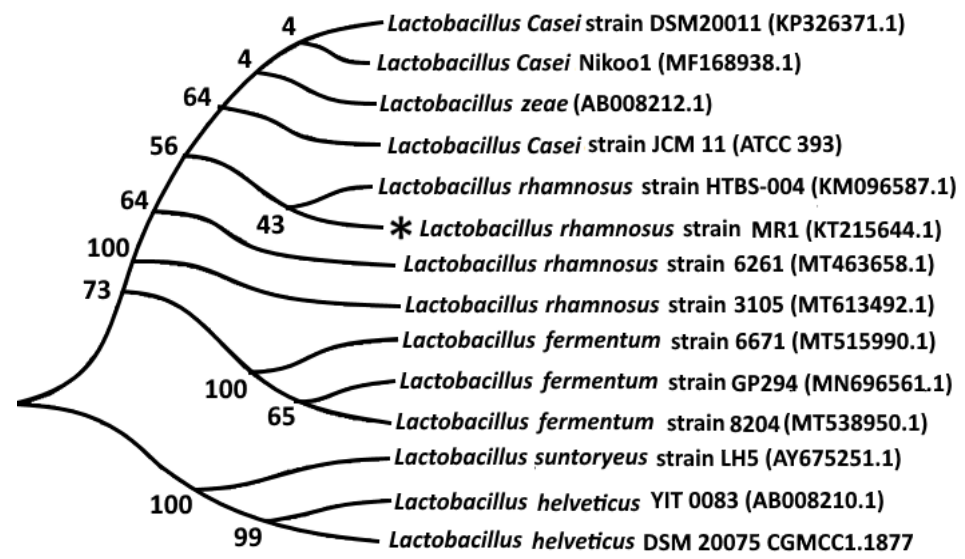

Figure 1. Phylogenetic tree of Lactobacillus strains and L. rhamnosus MR1 based on 16S rRNA gene sequences constructed by a neighbor-joining algorithm.

\subsection{The effects of $\mathrm{pH}$ and Bile salt on bacterium survival.}

Although L. rhamnosus MR1 showed remarkable tolerance to $\mathrm{pH}$ value in the neural condition, a significant level of living bacterial cells was obtained under the acidic conditions (Fig. 2A). One critical point in oral administration of probiotics is to survive their normal activities when they pass through the stomach in contact with a high acidic environment [13]. Gastric acid is an essential barrier against living probiotics in the gastrointestinal tract that can cause metabolism inhibition and enzyme inactivation in microorganisms $[14,15]$. On the other hand, cell viability declined gradually in high alkali conditions, as observed in acidic 
conditions. Therefore, one of the essential criteria for assessing the probiotic efficacy of bacteria is acid tolerance capacity that has been defined as the stability of their biological activities in acidic environments [13]. The strain MR1 exhibited a relatively acceptable tolerance in acidic conditions corresponding to the acid tolerance standard established based on several studies that most efficient probiotic strains could tolerate at least acidity level about $\mathrm{pH} 3.0$.

Bile salt (BS) tolerance of the strain MR1 was determined at a satisfactory level by exposure to $1.5 \%$ of BS for $1 \mathrm{~h}$. However, the highest viability was observed in control, which no bile salt presented in bacterial cells' contact (Fig. 2B). BS is mainly produced from cholesterol, in which the small intestine facilitates the uptake of fatty acids and cholesterol. Since the bile salts act as detergents, they facilitate the uptake of lipophilic nutrients from the gastrointestinal tract. Therefore, they can affect the bacterial membrane, both microbiota and pathogens [16].

Meanwhile, overexposure of probiotic microorganisms to BS causes lost cellular integrity, increasing membrane permeability, and ultimately cell death. The selection of those probiotic strains that would be capable of passing safely through the gastrointestinal tract is considered a serious challenge [13]. Therefore, to obtain effective probiotics, their ability to tolerate stomach acid, intestinal osmolarity, and high concentrations of bile acids must be considered [17]. The results obtained from the $\mathrm{pH}$ and $\mathrm{BS}$ tolerance tests implied that strain MR1 had promising administration characteristics as a nutraceutical compound that remained its bioactivity under gastrointestinal conditions.
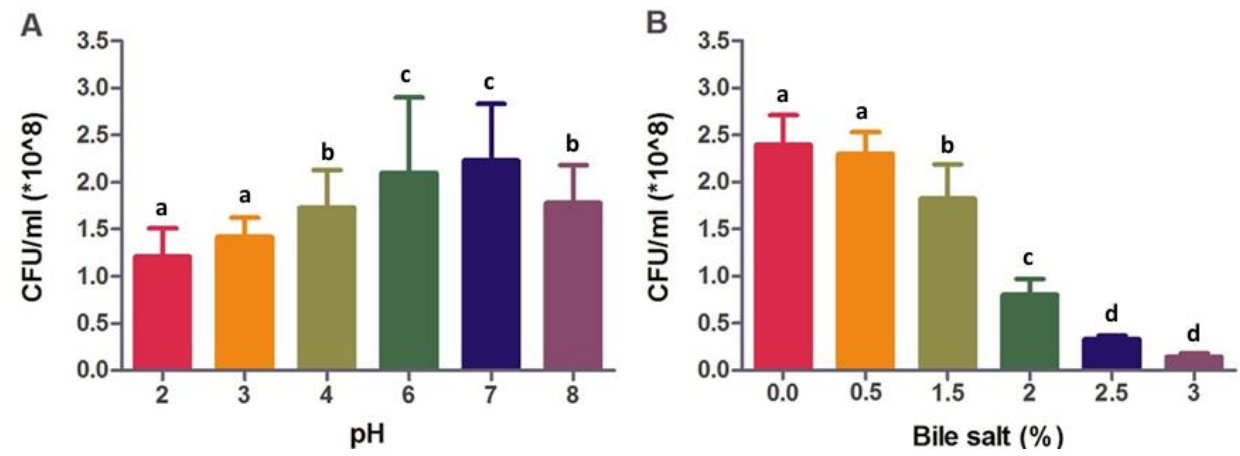

Figure 2. The effects of different $\mathrm{pHs}$ and bile salt concentrations on bacterial growth. The different letters indicate the significant differences between groups ( $\mathrm{p}$-value $<0.05$ ).

\subsection{Antibiotic resistance of L. rhamnosus MRI.}

Antibiotic susceptibility is the main criterion for evaluating the safety of probiotics. To assess the resistance to common antibiotics, the disc diffusion method is preferably used. As shown in Table 1, L. rhamnosus MR1 was susceptible to penicillin G and tetracycline. Strain MR1 showed intermediate resistance to erythromycin and azithromycin. Antibiotic resistance in probiotics is controversial in two respects, as resistant strains can benefit gastrointestinal microbiota during the treatment of bacterial infections.

On the other hand, antibiotic-resistant probiotics can donate genes to pathogenic species through conjugation $[18,19]$. Two antibiotic resistance types are found in bacterial strains, including innate (natural) and acquired resistance. The intrinsic type that originates the chromosome's resistance genes cannot be transferred horizontally to other bacterial strains. Numerous studies have reported vancomycin resistance in L. rhamnosus and L. reuteri is nontransferable due to its chromosomal origin. Some reports have attributed the development of 
multiple resistance in probiotics to spontaneous mutations [20]. Therefore, the transfer of antibiotic resistance traits to probiotics tends to be more beneficial than a threat [21]. In this research, L. rhamnosus MR1, with high resistance to widely used antibiotics, has demonstrated that it can have a strong protective function against injuries caused by long-term antibiotic use in patients.

Table 1. Antibiotic resistance profile of L. rhamnosus MR1.

\begin{tabular}{l|c|c|c} 
Antibiotic & Susceptibility status & MIC $(\boldsymbol{\mu g} / \mathbf{m l})$ & $\begin{array}{c}\text { Inhibition zone } \\
(\mathbf{m m})\end{array}$ \\
\hline Cephalexin & $\mathrm{R}$ & 300 & $8.5 \pm 0.72$ \\
\hline Ampicillin & $\mathrm{R}$ & 250 & $12 \pm 0.13$ \\
\hline Penicillin G & $\mathrm{S}$ & 10 & $24.6 \pm 1.3$ \\
\hline Tetracycline & $\mathrm{S}$ & 15 & $21.3 \pm 3.2$ \\
\hline Erythromycin & $\mathrm{MR}$ & 30 & $20.3 \pm 0.30$ \\
\hline Chloramphenicol & $\mathrm{R}$ & 150 & $8.04 \pm 0.38$ \\
\hline Streptomycin & $\mathrm{R}$ & 250 & $10.1 \pm 2.12$ \\
\hline Kanamycin & $\mathrm{R}$ & 350 & $5.6 \pm 0.61$ \\
\hline Azithromycin & $\mathrm{MR}$ & 25 & $13.7 \pm 3.2$ \\
\hline Ciprofloxacin & $\mathrm{R}$ & 400 & $0.0 \pm 00$
\end{tabular}

\subsection{In vitro cell adhesion ability of L. rhamnosus MRI.}

One of the features of probiotics is the ability to bind to and colonize gastrointestinal cells. As a result, the gastrointestinal tract's protection against infections and destructive factors is supported by increasing probiotics' compatibility. In this respect, various studies have demonstrated the regulating role of gastrointestinal microbiota in immune response and inflammatory reactions. [34]. Furthermore, the attachment of probiotics and their metabolites to the intestinal mucosa can function as a defensive shield. In this study, the L. rhamnosus MR1 showed that its ability to bind to Caco-2 cells was more than 50\%. As seen in Figure 3, the binding potential of bacteria is diminished by interactions with iron ions. According to other studies, bacterial cells may compete with chemicals and biology to bind to intestinal cells.

Zhai et al. (2016) reported reduced cadmium toxicity to intestinal epithelial cells, HT29 exposed to Lactobacillus plantarum [22]. Several reports have shown that L. rhamnosus strains are highly capable of detoxifying heavy metals such as cadmium, lead, and arsenic $[23,24]$.

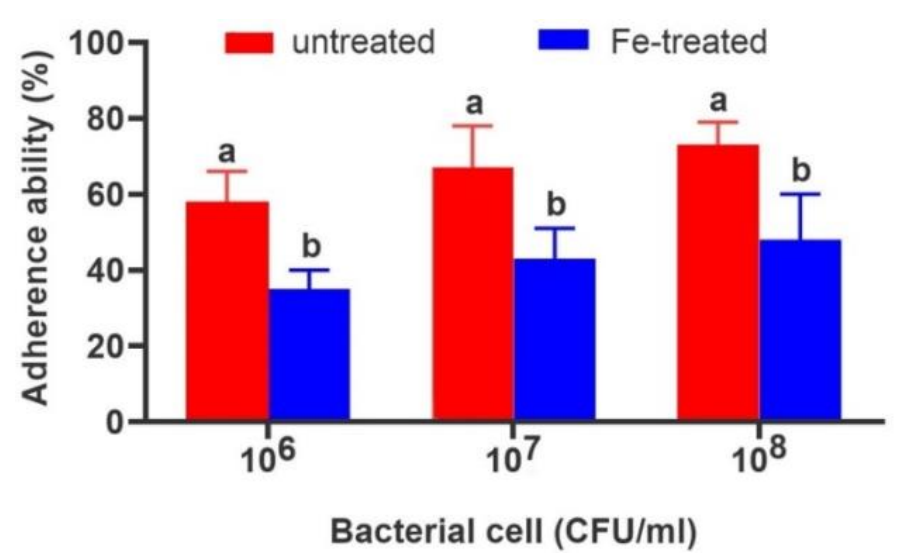

Figure 3. Adherence of L. rhamnosus MR1 to Caco- 2 cells. The different letters indicate the significant differences between groups ( $\mathrm{p}$-value<0.05).

L. rhamnosus supplementation has been shown to reduce heavy metals, especially iron, in pregnant women and children [4]. Some of the secretory peptides of probiotics neutralize food toxins such as aflatoxins that cause food poisoning [25]. This study's findings indicate 
that iron ions decrease the adherence of bacteria to Caco-2 cells. However, it can be proposed that probiotics may play a protective role against acute iron toxicity.

\subsection{Ferrous ion tolerance assay.}

The iron tolerance experiment showed that the strain MR1 could grow in the presence of a high level of ferrous sulfate in vitro. As seen in Figure 4, MIC for iron tolerance of the strain MR1 was determined $125 \mathrm{mg} / \mathrm{ml}$, and MBC value was estimated at $250 \mathrm{mg} / \mathrm{ml}$. Several mechanisms have occurred among various bacteria and metal ions, especially iron ions, including a ferric reduction to ferrous iron, siderophore production, and surface absorption by iron-binding proteins [26,27]. Since extracellular proteins are usually affected by environmental stress, such as electrochemical, osmolarity, and other physicochemical factors, a high level of the metal ions within the bacterial cell could influence the cellular metabolism and lead stress response [28]. A significant factor influencing bacteria's iron tolerance is the amount of soluble iron accessible for the bacterial cells to bacterial cells, increasing its absorption capacity [29].

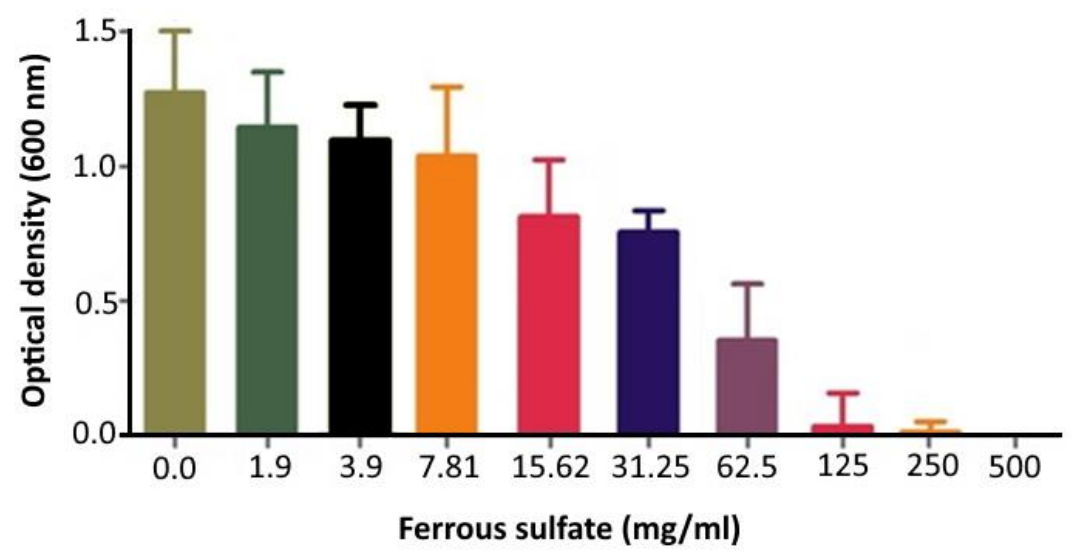

Figure 4. Iron tolerance by bacterial cells. The MIC value was determined based on the inhibition of iron growth in the MRS broth medium. MBC was calculated for those concentrations considered in the MIC assay.

\subsection{Cell hydrophobicity.}

Hydrophobicity of the strain MR1 was measured in hydrophobic phases, namely olive oil and n-hexane, in which different concentrations of ferrous ion and BS and different $\mathrm{pHs}$ were investigated. The results showed that the bacterial cells' hydrophobic tendency to the nhexane phase was more than the olive oil phase (Figure 5). On the other hand, cell hydrophobicity significantly decreased with the gradual increase of ferrous ion concentration. Similarly, hydrophobicity value in high concentrations of BS drastically declined to $1 \%$ when the bacterial cells were tested for their affinity to the olive oil as the hydrophobic phase. As a general result, the highest hydrophobicity was found in those experiments related to control without ferrous ion and bile salt treatments and $\mathrm{pH}$ 2. Bacterial cells have different extracellular molecules that provide surface charge for attachment of a wide range of materials, including glass, metals, and various organic polymers [30]. Therefore, the bacterial cells' attachment capacity depends on some surface energy such as surface charge, hydrophobic interactions that mediate possible absorptions to extracellular structures [31]. Also, bacterial cells, especially probiotic bacteria, often secret many secondary metabolites like bacteriocins, siderophores, and some peptides that promote attachment of chemical compounds and nutrients [32-34]. 

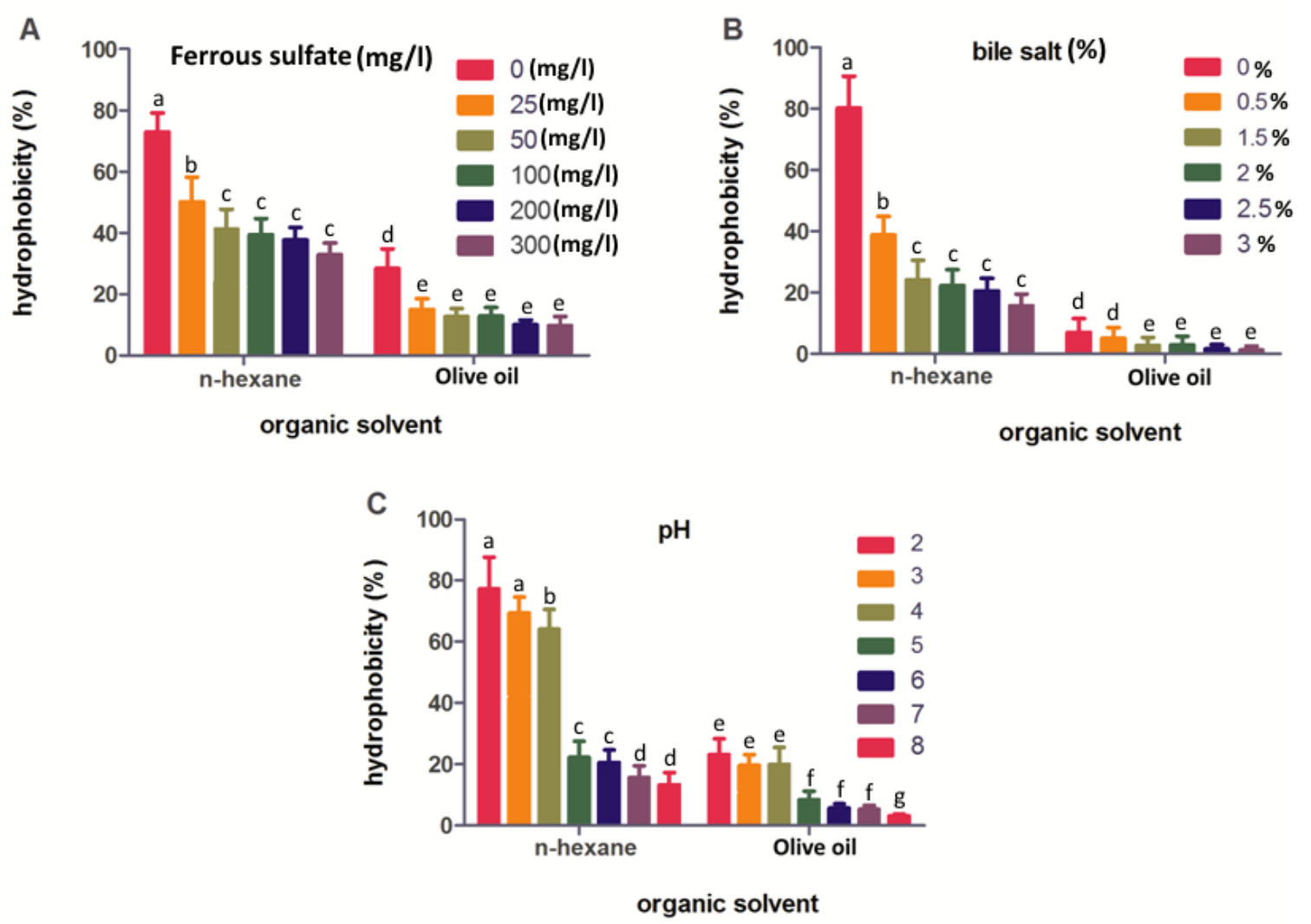

Figure 5. Hydrophobicity of the bacterial cells to two hydrophobic phases, n-hexan and olive oil, in different conditions. Hydrophobicity tendency of bacterial cells in the presence of (A) various iron concentrations. (B) different BS concentrations and (C) different $\mathrm{pHs}$.

\subsection{Anti-inflammatory activity of L. rhamnosus MRI.}

Three inflammatory mediators (IL-4, IL-8, and TNF- $\alpha$ ) were measured in the culture media from Caco-2 monolayers stimulated with iron sulfate or LPS and treated with $L$. rhamnosus MR1. As shown in Figure 6, a significant reduction was found in the IL-8 level in both LPS, and Fe stimulated groups. In contrast, the supplementation of probiotics had no significant amelioration in TNF- $\alpha$ level in all treatment groups. On the other hand, the level of anti-inflammatory cytokine IL-4 was drastically increased by $L$. rhamnosus MR1 supplementation in both LPS, and Fe stimulated groups. Considering the results, L. rhamnosus MR1 showed a significant role in the production of IL-4 by LPS or Fe-induced Caco- 2 cells, which is thought to result from its immune modulation of anti-inflammatory cytokines. On the other hand, the levels of pro-inflammatory factors, TNF- $\alpha$ and IL-8, rose even after probiotic administration in both groups induced by LPS and iron. Similarly, Devi et al. (2018) Showed that L. plantarum and L. rhamnosus supplementation did not have a significant effect on the expression of pro-inflammatory genes, such as IL-6, IL-8, IL-1 $\alpha$, IL-1 $\beta$, and TNF- $\alpha$ [35].

High doses of drugs and supplements, especially iron, can lead to acute inflammatory reactions in the gastrointestinal tract [5]. On the other hand, gut microbiota may modulate the inflammatory and oxidative stress response by affecting inflammatory cytokines. Although probiotics' influential role in stimulating the immune system, especially the gastrointestinal tract, has been investigated, probiotics' therapeutic role remains controversial [36]. Some scientists contend that probiotics simultaneously promote pro-inflammatory and antiinflammatory influences. For instance, some probiotic strains can lead to increased levels of TNF- $\alpha$ and then trigger IL-8 expression in the gut [37]. In contrast, Bahrami et al. (2011) 
concluded that HT-29 and Caco-2 cells treated with L. plantarum and Bifidobacterium adolescentis expressed high anti-inflammatory factors IL-4 and IL-10. On the other hand, they claimed probiotics such as L. acidophilus, L. rhamnosus, and L. paracasei significantly decreased IL-4 expression levels during the inflammatory process [38].
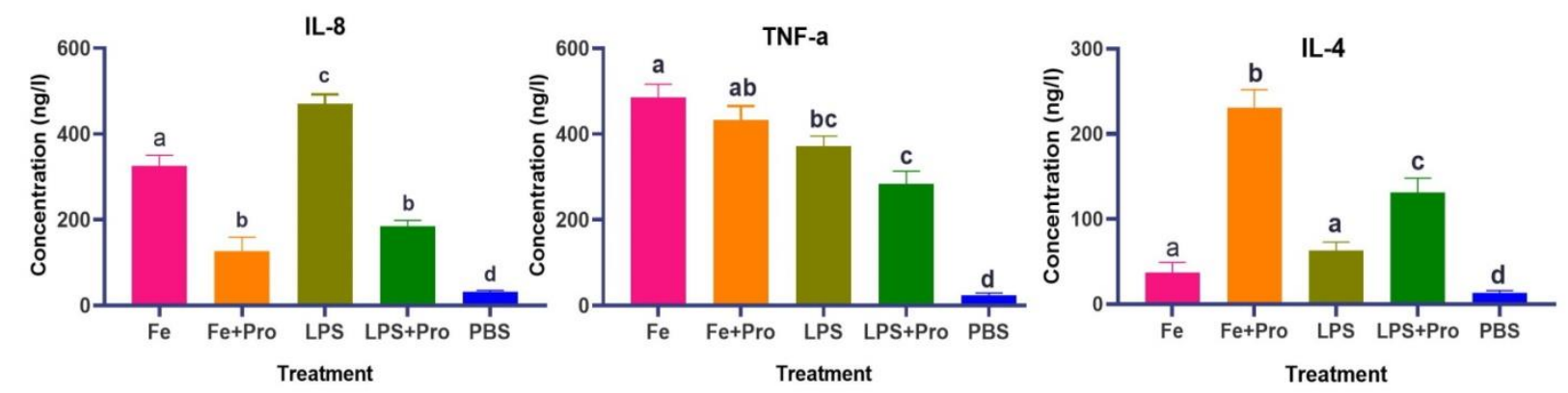

Figure 6. Level of pro- and anti-inflammatory cytokines A) IL-8, B) TNF- $\alpha$, and C) IL-4 during LPS- and Feinduced Caco- 2 cells after treatment with L. rhamnosus MR1. The values represented are the gene expression fold change mean average \pm SD $(n=3)$. The different alphabetical superscripts are defined as statistically significant $(\mathrm{p}<0.05)$.

\subsection{Antioxidant activity of L. rhamnosus MR1.}

The DPPH scavenging assay evaluated antioxidant activity of L. rhamnosus MR1. The DPPH scavenging assay was recognized as a promising technique for the antioxidant potential of bioactive compounds. This method measures the proton donation capacity of antioxidants to DPPH radicals [36]. As seen in Figure 7, the antioxidant capacity of L. rhamnosus MR1 was found to be $47 \%$ at the highest concentration compared with ascorbic acid (100\%). As the concentration of probiotic metabolites in the CFS decreased, so did the antioxidant activity. In this experiment, the highest antioxidant activity was $47 \%$ for a cell density of approximately $3 \times 10^{8} \mathrm{CFU} / \mathrm{ml}\left(\mathrm{OD}_{600}=1.0\right)$.

Similarly, Ghafari and Ansari (2018) showed that CFS of L. casei and L. rhamnosus had an antioxidant capacity of about 45\% [39]. According to the studies, metabolites of probiotics contain different compounds with various bioactive properties such as antioxidant, anticancer, antimicrobial, etc. These compounds are often composed of low-weight peptides, exopolysaccharides, surfactants, antibiotics, and active short-chain fatty acids. Ji et al. (2015) noted that many Lactobacillus strains produce low molecular weight metabolites with remarkably high antioxidant capacity that can neutralize various toxins and mutagenic substances [40]. In this study, L. rhamnosus MR1 had a promising antioxidant potential that could reduce iron ions' acute toxicity in the intestine.

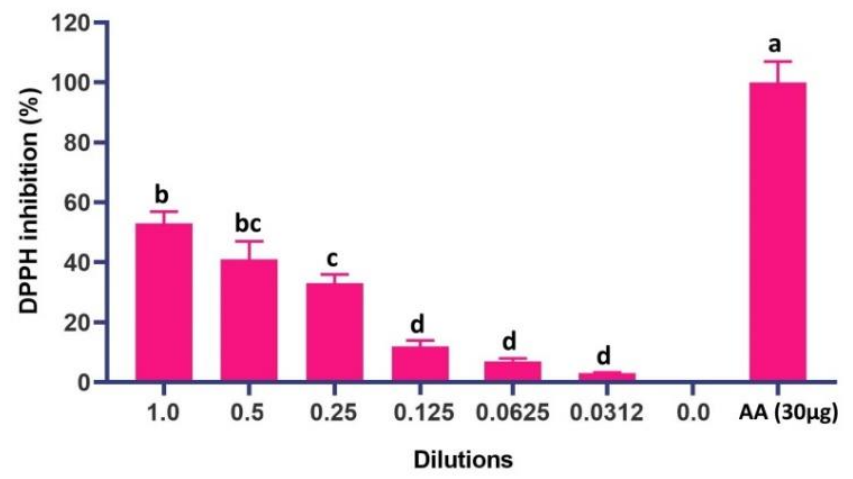

Figure 7. Antioxidant activity of L. rhamnosus MR1 in serial dilutions compared with ascorbic acid (AA). Different superscript alphabetic shows a significant difference between groups $(\mathrm{P}$-value $<0.05)$. 


\subsection{Animal experiments.}

Prophylactic and ameliorative effects of L. rhamnosus MR1 in rats caused a significant reduction in intestinal iron uptake by $50 \%$ during $6 \mathrm{~h}$. However, the Prophylactic assay of $L$. rhamnosus MR1 on acute iron toxicity showed no significant difference to ameliorative effect when overdose iron feeding (Figure 8). Therefore, iron sequestration may be associated with the extracellular absorption capacity of the bacterial cells. In this regard, Skrypnik et al. (2018) reported that supplementation of multispecies probiotics, including 9 different bacterial strains, significantly reduced acute iron toxicity in rats [41]. According to studies, gut microbiota plays a vital role in the absorption, neutralization, and chemical changes in food compositions. As the gastrointestinal tract's pivotal living components, probiotics profoundly impact the processing of nutrients and toxic substances [4,8]. Since the bacterium MR1 has demonstrated a remarkable ability to bind to epithelial cells, it can compete with absorbable materials and even pathogens, mitigating its harmful effects.
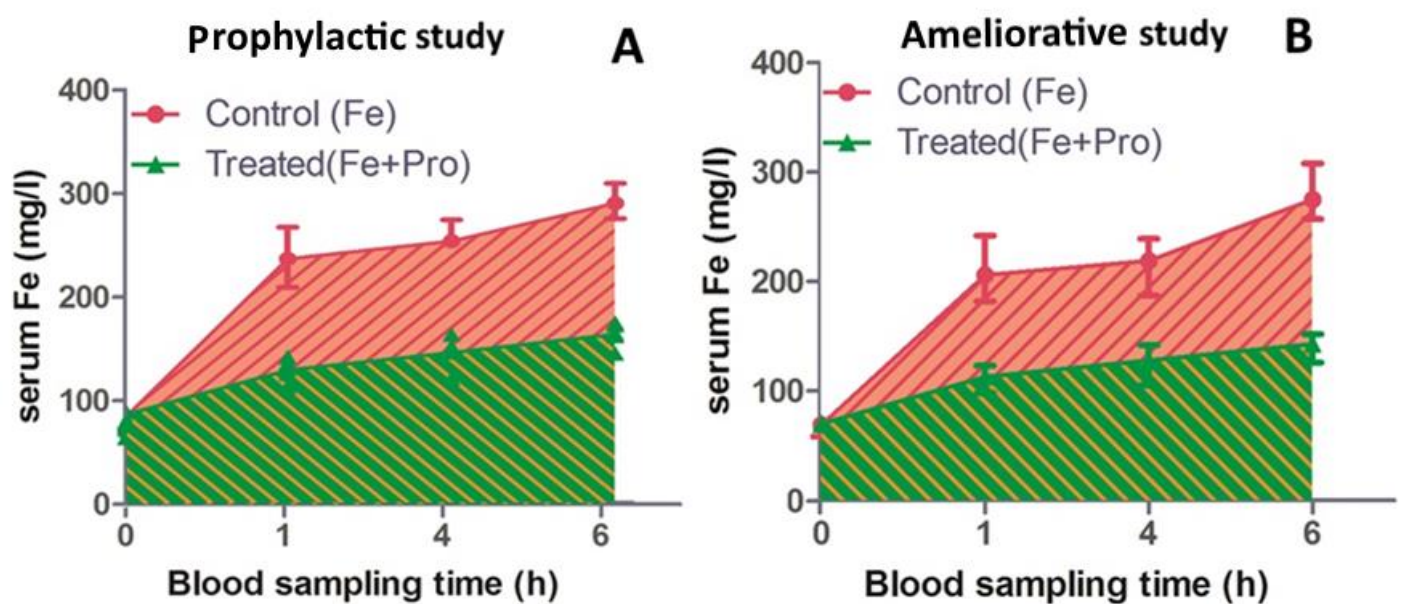

Figure 8. Iron binding abilities of probiotic bacteria. A. Prophylactic effect of L. rhamnosus for 2 weeks on overdose supplementation of iron sulfate and B. Ameliorative effects of L. rhamnosus on intestinal absorption of iron sulfate. The results are presented in three replicates with standard deviation. Total serum iron was measured in 6-h time intervals after treatment with probiotic and then ferrous sulfate.

\section{Conclusions}

This study concluded that L. rhamnosus MR1 effectively increases iron tolerance in vitro and mitigating iron toxicity in vivo. The results showed the potential of L. rhamnosus MR1 on decreasing lethality after overdose administration of ferrous sulfate and induction of acute toxicity in rats. Since no report is found in the current literature about the effect of probiotic supplements on iron's acute toxicity, these interesting results can provide a useful background for further studies on dietary supplements.

\section{Funding}

This work was financially supported by Mashhad University of Medical Sciences with grant number 931416. The authors declare that no potential conflict of interest relevant to the present study.

\section{Acknowledgments}

This research has no acknowledgment. 


\section{Conflicts of Interest}

\section{The authors declare no conflict of interest.}

\section{References}

1. Conway, D.; Henderson, M.A. Iron metabolism. Anaesthesia \& Intensive Care Medicine 2019, 20, 175-177, https://doi.org/10.1016/j.mpaic.2019.01.003.

2. Lopez, A.; Cacoub, P.; Macdougall, I.C.; Peyrin-Biroulet, L. Iron deficiency anaemia. The Lancet 2016, 387, 907-916, https://doi.org/10.1016/S0140-6736(15)60865-0.

3. Saporito-Magriñá, C.; Musacco-Sebio, R.; Acosta, J.M.; Bajicoff, S.; Paredes-Fleitas, P.; Reynoso, S.; Boveris, A.; Repetto, M.G. Copper(II) and iron(III) ions inhibit respiration and increase free radicalmediated phospholipid peroxidation in rat liver mitochondria: Effect of antioxidants. Journal of Inorganic Biochemistry 2017, 172, 94-99, https://doi.org/10.1016/j.jinorgbio.2017.04.012.

4. Abdel-Megeed, R.M. Probiotics: a Promising Generation of Heavy Metal Detoxification. Biological trace element research 2020, 1-8, https://doi.org/10.1007/s12011-020-02350-1.

5. Halil, H.; Tuygun, N.; Polat, E.; Karacan, C.D. Minimum ingested iron cut-off triggering serious iron toxicity in children. Pediatrics international 2019, 61, 444-448, https://doi.org/10.1111/ped.13834.

6. Sane, M.R.; Malukani, K.; Kulkarni, R.; Varun, A. Fatal iron toxicity in an adult: Clinical profile and review. Indian journal of critical care medicine 2018, 22, 801-803.

7. Mobarra, N.; Shanaki, M.; Ehteram, H.; Nasiri, H.; Sahmani, M.; Saeidi, M.; Goudarzi, M.; Pourkarim, H.; Azad, M. A review on iron chelators in treatment of iron overload syndromes. International journal of hematology-oncology and stem cell research 2016, 10, 239-247.

8. Alok, A.; Singh, I.D.; Singh, S.; Kishore, M.; Jha, P.C.; Iqubal, M.A. Probiotics: A new era of biotherapy. Advanced biomedical research 2017, 6, https://doi.org/10.4103/2277-9175.192625.

9. Quigley, E.M. Prebiotics and probiotics in digestive health. Clinical Gastroenterology Hepatology 2019, 17, 333-344, https://doi.org/10.1016/j.cgh.2018.09.028.

10. Sharma, M.; Chandel, D.; Shukla, G. Antigenotoxicity and Cytotoxic Potentials of Metabiotics Extracted from Isolated Probiotic, Lactobacillus rhamnosus MD 14 on Caco-2 and HT-29 Human Colon Cancer Cells. Nutrition and cancer 2020, 72, 110-119, https://doi.org/10.1080/01635581.2019.1615514.

11. Mohseni, S.; Marzban, A.; Sepehr, S.; Hosseinkhani, S.; Karkhaneh, M.; Azimi, A. Investigation of some heavy metals toxicity for indigenous Acidithiobacillus ferrooxidans isolated from sarcheshmeh copper mine. Jundishapur Journal of Microbiology 2011, 4, 159-166.

12. Heravi, R.M.; Kermanshahi, H.; Sankian, M.; Nassiri, M.; Moussavi, A.H.; Nasiraii, L.R.; Varasteh, A. Screening of lactobacilli bacteria isolated from gastrointestinal tract of broiler chickens for their use as probiotic. African Journal of Microbiology Research 2011, 5, 1858-1868.

13. Wan, D.; Wu, Q.; Ni, H.; Liu, G.; Ruan, Z.; Yin, Y. Treatments for iron deficiency (ID): prospective organic iron fortification. Current pharmaceutical design 2019, 25, 325-332, https://doi.org/10.2174/1381612825666190319111437.

14. Yang, S.J.; Lee, J.E.; Lim, S.M.; Kim, Y.J.; Lee, N.K.; Paik, H.D. Antioxidant and immune-enhancing effects of probiotic Lactobacillus plantarum 200655 isolated from kimchi. Food Science and Biotechnology, 2019, 28, 491-499, https://doi.org/10.1007/s10068-018-0473-3.

15. Kim, J.; Muhammad, N.; Jhun, B.H.; Yoo, J.-W. Probiotic delivery systems: a brief overview. Journal of Pharmaceutical Investigation 2016, 46, 377-386, https://doi.org/10.1007/s40005-016-0259-7.

16. Jia, W.; Xie, G.; Jia, W. Bile acid-microbiota crosstalk in gastrointestinal inflammation and carcinogenesis. Nature Reviews Gastroenterology and Hepatology 2018, 15, 111-128, https://doi.org/10.1038/nrgastro.2017.119.

17. Kumaree, K.K.; Akbar, A.; Anal, A.K. Bioencapsulation and application of Lactobacillus plantarum isolated from catfish gut as an antimicrobial agent and additive in fish feed pellets. Annals of Microbiology 2015, 65, 1439-1445, https://doi.org/10.1007/s13213-014-0982-0.

18. Das, D.J.; Shankar, A.; Johnson, J.B.; Thomas, S. Critical insights into antibiotic resistance transferability in probiotic Lactobacillus. Nutrition, 2020, 69, 110567, https://doi.org/10.1016/j.nut.2019.110567

19. Jose, N.M.; Bunt, C.R.; Hussain, M.A. Implications of antibiotic resistance in probiotics. Food Reviews International 2015, 31, 52-62, https://doi.org/10.1080/87559129.2014.961075.

20. Lokesh, D.; Rajagopal, K.; Shin, J.H. Multidrug Resistant Probiotics as an Alternative to Antibiotic Probiotic therapy. Journal of Infectiology 2019, 2, 46-49.

21. Kang, W.; Pan, L.; Peng, C.; Dong, L.; Cao, S.; Cheng, H.; Wang, Y.; Zhang, C.; Gu, R.; Wang, J. Isolation and characterization of lactic acid bacteria from Chinese human milk. Journal of Dairy Science 2020, 103, 9980-9991, https://doi.org/10.3168/jds.2020-18704.

22. Zhai, Q.; Tian, F.; Zhao, J.; Zhang, H.; Narbad, A.; Chen, W. Oral administration of probiotics inhibits absorption of the heavy metal cadmium by protecting the intestinal barrier. Appl. Environ. Microbiol. 2016, 82, 4429-4440, https://doi.org/10.1128/AEM.00695-16. 
23. de Matuoka e Chiocchetti, G.; Monedero, V.; Zúñiga, M.; Vélez, D.; Devesa, V. In Vitro Evaluation of the Protective Role of Lactobacillus StrainsAgainst Inorganic Arsenic Toxicity. Probiotics and Antimicrobial Proteins 2020, 12, 1484-1491, https://doi.org/10.1007/s12602-020-09639-6.

24. Daisley, B.A.; Monachese, M.; Trinder, M.; Bisanz, J.E.; Chmiel, J.A.; Burton, J.P.; Reid, G. Immobilization of cadmium and lead by Lactobacillus rhamnosus GR-1 mitigates apical-to-basolateral heavy metal translocation in a Caco-2 model of the intestinal epithelium. Gut microbes 2019, 10, 321-333, https://doi.org/10.1080/19490976.2018.1526581.

25. Assaf, J.C.; Khoury, A.E.; Chokr, A.; Louka, N.; Atoui, A. A novel method for elimination of aflatoxin M1 in milk using Lactobacillus rhamnosus GG biofilm. International Journal of Dairy Technology 2019, 72, 248-256, https://doi.org/10.1111/1471-0307.12578.

26. Bailey, J.R.; Probert, C.S.; Cogan, T.A. Identification and characterisation of an iron-responsive candidate probiotic. PloS one 2011, 6, https://doi.org/10.1371/journal.pone.0026507.

27. Reyes-Mendez, A.; Figueroa-Hernandez, C.; Melgar-Lalanne, G.; Hernandez-Sanchez, H.; Dávila-Ortiz, G.; Jiménez-Martínez, C. Production of calcium-and iron-binding peptides by probiotic strains of Bacillus subtilis, B. clausii and B. coagulans GBI-30. Revista Mexicana de Ingeniería Química 2015, 14, 1-9.

28. Patel, A.K.; Deshattiwar, M.K.; Chaudhari, B.L.; Chincholkar, S.B. Production, purification and chemical characterization of the catecholate siderophore from potent probiotic strains of Bacillus spp. Bioresource technology 2009, 100, 368-373, https://doi.org/10.1016/j.biortech.2008.05.008.

29. Hoppe, M.; Önning, G.; Berggren, A.; Hulthén, L. Probiotic strain Lactobacillus plantarum 299v increases iron absorption from an iron-supplemented fruit drink: a double-isotope cross-over single-blind study in women of reproductive age. British Journal of Nutrition 2015, 114, 1195-1202, https://doi.org/10.1017/S000711451500241X.

30. Jeffery, C.J. Intracellular/surface moonlighting proteins that aid in the attachment of gut microbiota to the host. AIMS Microbiology, 2019, 5, 77-88, https://doi.org/10.3934/microbiol.2019.1.77.

31. Guo, K.; Freguia, S.; Dennis, P.G.; Chen, X.; Donose, B. C.; Keller, J.; Gooding, J. J.; Rabaey, K. Effects of surface charge and hydrophobicity on anodic biofilm formation, community composition, and current generation in bioelectrochemical systems. Environmental science \& technology 2013, 47, 7563-7570, https://doi.org/10.1021/es400901u.

32. Mrvčić, J.; Stanzer, D.; Šolić, E.; Stehlik-Tomas, V. Interaction of lactic acid bacteria with metal ions: opportunities for improving food safety and quality. World Journal of Microbiology and Biotechnology 2012, 28, 2771-2782, https://doi.org/10.1007/s11274-012-1094-2.

33. Angelopoulou, A.; Warda, A.K.; O’Connor, P.M.; Stockdale, S.R.; Shkoporov, A.N.; Field, D.; Draper, L.A.; Stanton, C.; Hill, C.; Ross, R.P. Diverse Bacteriocins Produced by Strains From the Human Milk Microbiota. Frontiers in Microbiology, 2020, 11, 788, https://doi.org/10.3389/fmicb.2020.00788.

34. Galdeano, C.M.; Cazorla, S.I.; Dumit, J.M.L.; Vélez, E.; Perdigón, G. Beneficial effects of probiotic consumption on the immune system. Annals of Nutrition and Metabolism, 2019, 74, 115-124. https://doi.org/10.1159/000496426

35. Devi, S.M.; Kurrey, N.K.; Halami, P.M. In vitro anti-inflammatory activity among probiotic Lactobacillus species isolated from fermented foods. Journal of Functional Foods 2018, 47, 19-27, https://doi.org/10.1016/j.jff.2018.05.036.

36. Kobatake, E.; Nakagawa, H.; Seki, T.; Miyazaki, T. Protective effects and functional mechanisms of Lactobacillus gasseri SBT2055 against oxidative stress. PloS one 2017, 12, https://doi.org/10.1371/journal.pone.0177106.

37. Candela, M.; Perna, F.; Carnevali, P.; Vitali, B.; Ciati, R.; Gionchetti, P.; Rizzello, F.; Campieri, M.; Brigidi, P. Interaction of probiotic Lactobacillus and Bifidobacterium strains with human intestinal epithelial cells: adhesion properties, competition against enteropathogens and modulation of IL-8 production. International Journal of Food Microbiology 2008, 125, 286-292, https://doi.org/10.1016/j.ijfoodmicro.2008.04.012.

38. Bahrami, B.; Macfarlane, S.; Macfarlane, G. Induction of cytokine formation by human intestinal bacteria in gut epithelial cell lines. Journal of Applied Microbiology 2011, 110, 353-363, https://doi.org/10.1111/j.1365-2672.2010.04889.x.

39. Ghafari, S.; Ansari, S. Microbial viability, physico-chemical properties and sensory evaluation of pineapple juice enriched with Lactobacillus casei, Lactobacillus rhamnosus and inulin during refrigerated storage. Journal of Food Measurement Characterization 2018, 12, 2927-2935, https://doi.org/10.1007/s11694-0189908-z.

40. Ji, K.; Jang, N.Y.; Kim, Y.T. Isolation of lactic acid bacteria showing antioxidative and probiotic activities from kimchi and infant feces. Journal of Microbiolology and Biotechnology 2015, 25, 1568-1577, https://doi.org/10.4014/jmb.1501.01077.

41. Skrypnik, K.; Bogdański, P.; Łoniewski, I.; Reguła, J.; Suliburska, J. Effect of probiotic supplementation on liver function and lipid status in rats. Acta Scientiarum Polonorum Technologia Alimentaria 2018, 17, 185 192, https://doi.org/10.17306/J.AFS.0554. 